\title{
A Note on Probability of Occurrence of Largest Earthquake in Jharkhand State (India) and Nearby Region Based on Gumbel's Extreme Value Theory
}

\author{
V K Srivastava , Akash Adwani, Akshat Saxena, Yogesh Arora \\ Department of Applied Geophysics, Indian School of Mines, Dhanbad,India \\ *Corresponding Author: ismkvinay@gmail.com
}

Copyright @ 2014 Horizon Research Publishing All rights reserved.

\begin{abstract}
Seismicity of Jharkhand state resembles to that of Stable Continental Region (SCR) and has experienced nearly 30 earthquakes of magnitudes ranging from 3 to 6 during the last 147 years. These earthquakes are shallow and crustal in nature which are scattered all over the region. However during the last 10 to 15 years there has been increase in the occurrence of seismic events. The study of plot of earthquake energy release versus time indicates that the earthquake of magnitude 6 may occur in and around the year 2060. The probabilistic analysis shows a high probability of occurrence of seismic events with $\mathrm{M}>5$ in 50 years of time interval and such interval increases with increase of earthquake magnitude. The return period for magnitudes 6 and above is quite high ( 80 to 100 years) where as for lower magnitudes the probability of occurrence ranges from 7 to 22 years. This periodicity of 100 years for magnitude 6 is approximately matching with the trend of magnitude energy release plot. However in view of the development and upcoming of high rise buildings in the region the smaller events and longer return period of damaging earthquake must not be ignored.
\end{abstract}

Keywords Seismicity, Magnitude, Probability, Return period

\section{Introduction}

The state of Jharkhand is carved out of the erstwhile state of Bihar (India) on 15 November 2000 and extends from $21^{\circ} 58^{\prime} 10^{\prime \prime} \mathrm{N}$ to $25^{\circ} 19^{\prime} 15^{\prime \prime} \mathrm{N}$ Latitude and from $83^{\circ} 20^{\prime} 50^{\prime \prime} \mathrm{E}$ to $88^{\circ} \dot{4}^{\prime} 40^{\prime}$ "E Longitude (with north-south extension of about $380 \mathrm{~km}$ and east-west extension of $463 \mathrm{~km}$ ). The region is typically marked by varied type of geomorphic features ( Fig.1) viz.; i) the Vindhayn plateau extending into the Rohtas region ii) the Damodar Valley Coal bearing Gondwana basin iii) Rajmahal belt in east iv) the Satpura range extending into southern central large tract of the state and v) the Chhotanagpur Plateau (CNP) in south which is bounded by the Mahanadi Gondwana basin forming as broad belt and then extending linearly south westward to central India, Mahadevan (2002). Seismically the region is not very active though in past few records of damages supposedly due to earthquakes have been recorded in the literature which might be due to earthquakes occurred in the region itself or could have been originated in the northern active Himalayan region. Here no regular pattern of earthquake occurrence has been observed except alignment of few events along the faulted margin of crystalline and sedimentary gondwana basin. However the proximity to faults does not translate the region into high seismicity or in high risk zone and depends on factors such as subsurface geology and adherence to the building codes (Narula et al 2000). But in recent past, Jharkhand State has experienced moderate to fairly high seismicity with record of small tremors along the borders of adjoining Indian states viz.; Bihar, Orissa and West Bengal and the area being the hub of the coal mining and allied industries the developments in the region is taking place at faster rate and even this low seismicity is of concern to civil engineers and all aspects should be studied well.

In present paper statistical approach of Extreme Value Theory as described by Gumbel (1958) has been carried out to calculate the probability of occurrence of event of certain magnitude using data set for a period 1862 to 2009 down loaded from USGS site and this method has been applied by various workers viz.; Schenkova and Karnik (1970); Karnik and Schenkova (1974); Srivastava et al (1976), Tezcan(1996) in various regions of the world.

\section{Seismicity of the Region}

In order to understand the spatial pattern of earthquake occurrence seismicity map of the region has been prepared as shown in Fig. 2 using the earthquake data set from USGS catalog for the period 1862 to 2009. From the map it is quite clear that the seismicity is quite scattered and are not associated with tectonic features of the region. This shows that tectonically the region is quite stabel and hence the region is the Stable Continental Region (SCR). 


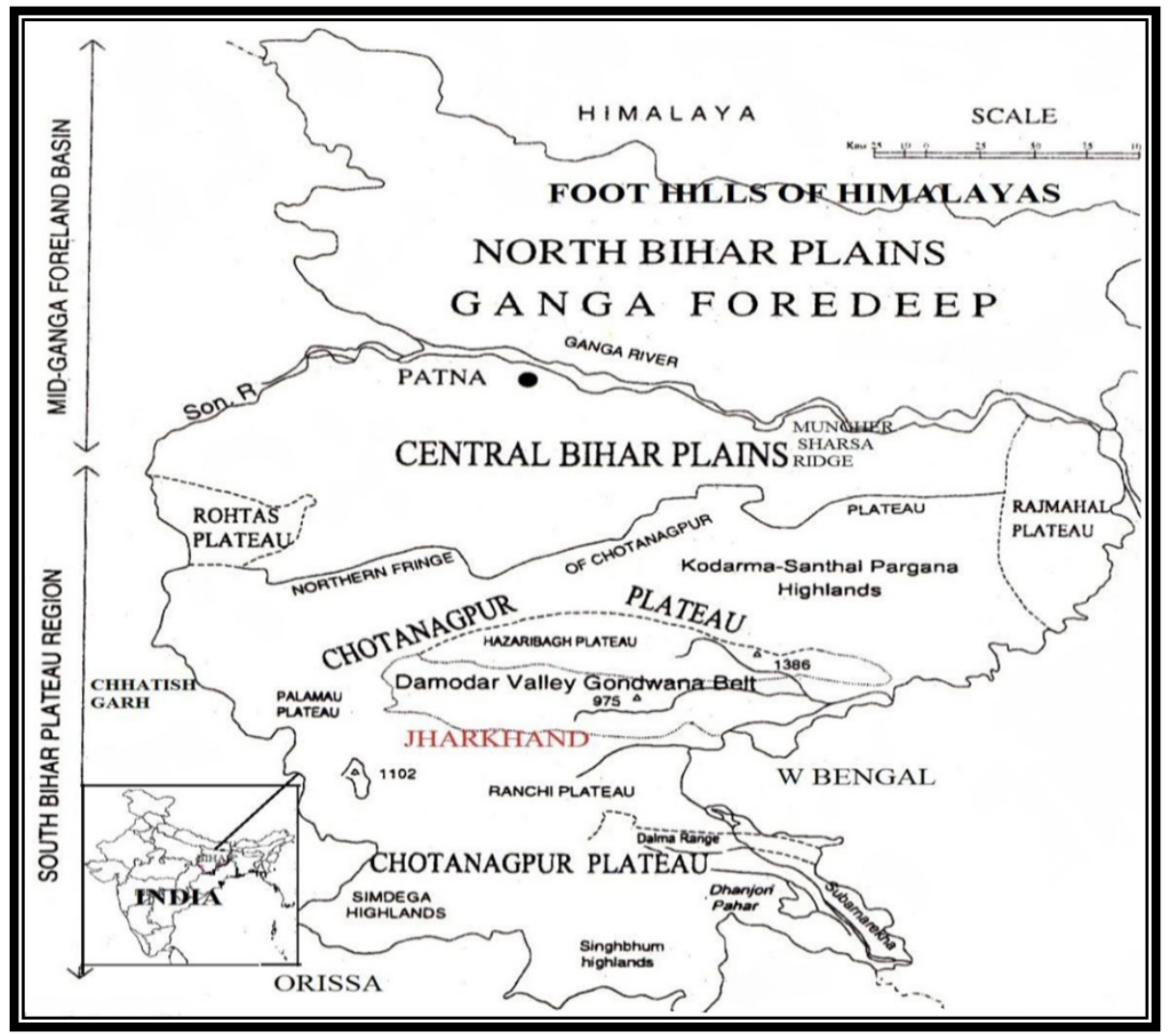

Figure 1. Geomorphology of Jharkhand State and adjoining Bihar region (After Mahdevan,2000)

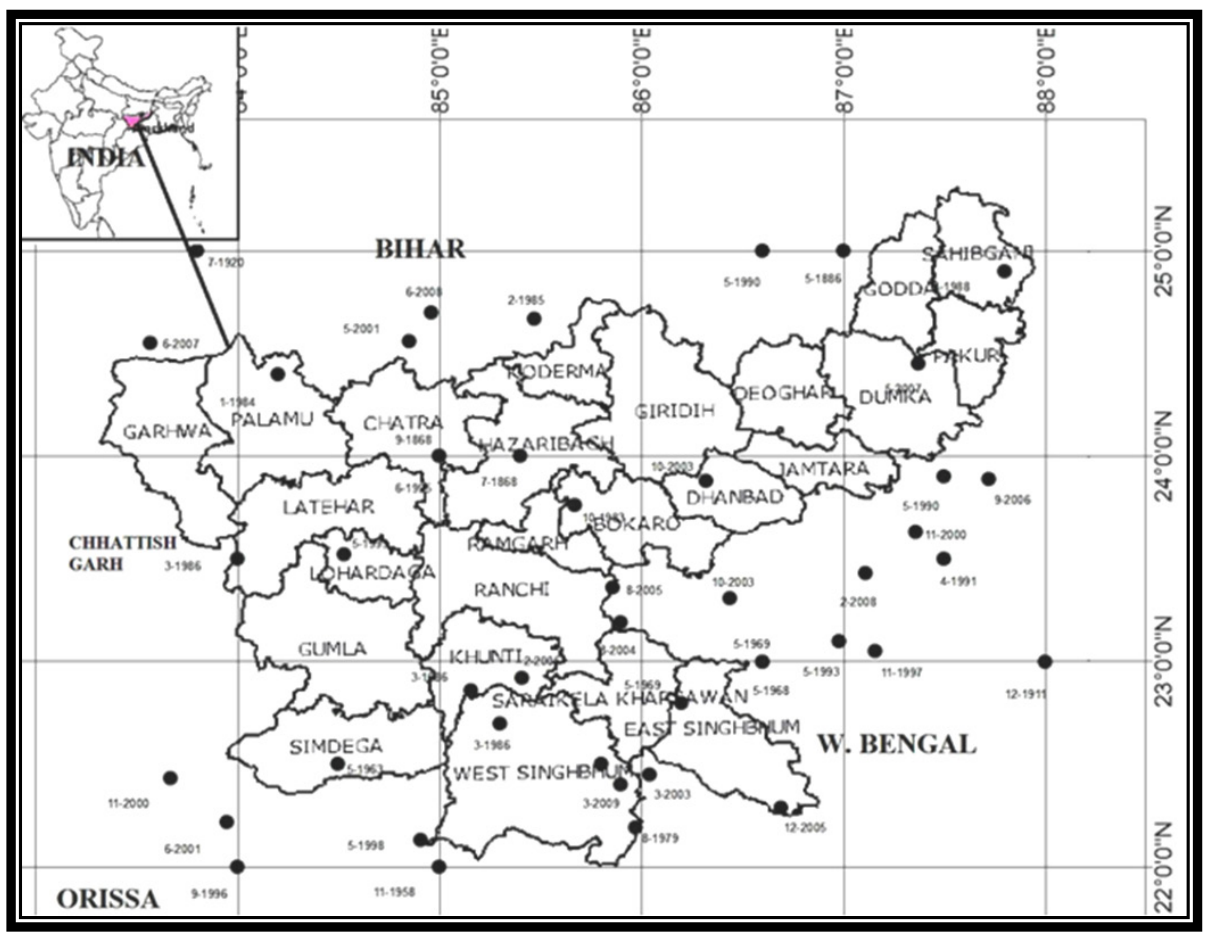

Figure 2 . Seismicity Map of Jharkhand and nearby region from 1862 to 2009 ,Earthquake epicenter along with month and year (mm-yyyy) of occurrence 


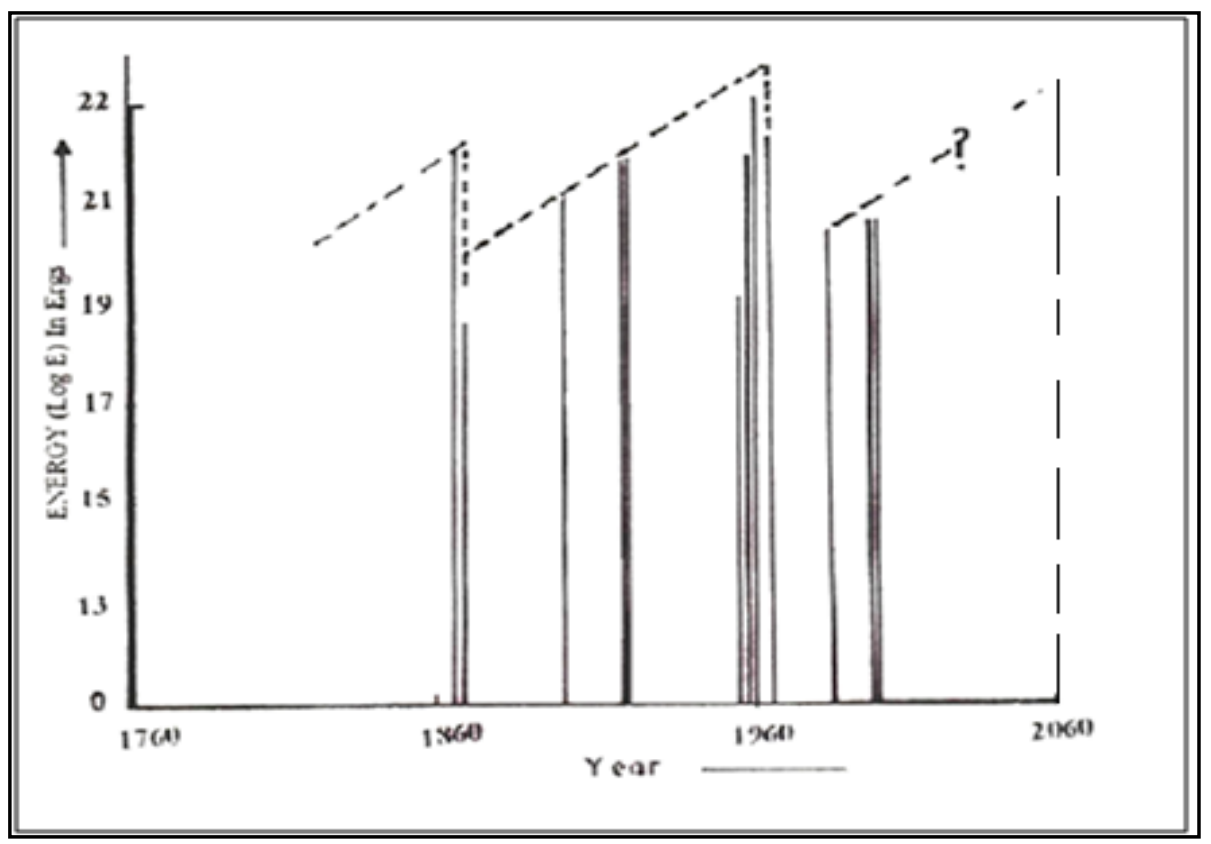

Figure 3. A plot of annual earthquake energy release occurred during 1862-2009.

\section{Pattern of Earthquake Energy Released}

As the energy propagated by the seismic wave is proportional to the square of the amplitude and thus the magnitude is proportional to the logarithm of the energy. But this energy is not the intrinsic energy released from the source such as gravitational energy or to sink such as heat energy.

The Fig. 3 shows a plot between earthquake energy release and year covering a data period from 1862 to 2009 . The earthquake energy (in Ergs ) has been calculated using empirical relation between magnitude and energy as given by Gutenberg and Richter (1956). The study of this annual earthquake energy release for the period 1862 to 2009 shows a cyclic pattern of energy release with repeat period of 100 years ie maxima of energy release (corresponding to magnitude $>6$ ) occurs in and around 1760, 1860,1960 and accordingly now the next maximum will occur in and around 2060 with probable highest magnitude of 6 and above.

\section{Application of Gumbel'S Extreme Values Method to Jharkhand State and Nearby Region}

Gutenberg - Richter described a methodology for estimating the magnitudes of future earthquakes using the past earthquakes. However, as it is difficult to have complete data set and therefore the Gumbel's Annual Extreme Value
Method which is concern with the largest past earthquakes is found to be useful and meaningful. According to this, G(M): the Probability of occurrence of earthquake not exceeding the magnitudes more than $\mathrm{M}$ in one year is given by

$$
G(M)=e^{(\alpha \exp (-\beta M))}
$$

where M: the largest magnitude of earthquake in one year, $\alpha, \beta$ : regression coefficients

But in 1956 , Gutenberg- Richter proposed the following equation relating the earthquake magnitude to the total number of earthquakes in one year:

$$
\log (\mathrm{N})=\mathrm{a}-\mathrm{bM}
$$

where a,b: regressions coefficients

$\mathrm{N}$ : the number of earthquakes in one year whose magnitude is equal to $\mathrm{M}$ or greater.

The coefficients of Gumbel's and Richter's relation could be related as given below:

$$
\begin{gathered}
\alpha=10^{\mathrm{a}}, \mathrm{a}=\log (\alpha) \\
\beta=\mathrm{b} / \log (\mathrm{e}), \mathrm{b}=\beta \log (\mathrm{e}) \\
\mathrm{N}=\alpha \mathrm{e}-\beta \mathrm{M}=-\ln (\mathrm{G})
\end{gathered}
$$

In order to find Gumbel's regressions coefficients, firstly maximum earthquakes for every year have been taken from USGS and other catalogues as shown in Table 1. We have assumed $\mathrm{M}_{\max }=3$ for the years in which with no earthquakes could be recorded, i.e. a background seismicity of the region and the number of this earthquake (j) and relative frequency $(f=j /(n+1))$ have been determined during the investigated seismic history period. 
Table 1. Annual maximum earthquake magnitudes(in Mb) for time interval $1866-2009$

\begin{tabular}{cccccc}
\hline Year & Mmax & Year & Mmax & Year & Mmax \\
\hline 1866 & 5.5 & 1984 & 4.0 & 2000 & 3.0 \\
1868 & 5.7 & 1985 & 4.7 & 2001 & 4.8 \\
1911 & 5.0 & 1986 & 4.5 & 2003 & 4.3 \\
1920 & 5.5 & 1988 & 4.9 & 2004 & 3.6 \\
1958 & 4.0 & 1990 & 5.4 & 2005 & 3.8 \\
1962 & 4.0 & 1991 & 3.6 & 2006 & 3.7 \\
1963 & 6.0 & 1993 & 4.6 & 2007 & 3.8 \\
1968 & 5.6 & 1995 & 3.8 & 2008 & 4.3 \\
1969 & 3.9 & 1996 & 4.2 & 2009 & 4.1 \\
1979 & 4.7 & 1998 & 4.5 & & \\
1983 & 3.8 & 1999 & 4.0 & & \\
\hline
\end{tabular}

(We have assumed $\mathrm{M} \max =3$ for years with no earthquakes)

Table 2. Values of calculated Gumbel's Annual Maximum Magnitude

\begin{tabular}{ccccc}
\hline $\mathrm{M}$ & $\mathrm{j}$ & $\mathrm{G}(\mathrm{M})$ & $\mathrm{N}=-\ln (\mathrm{G})$ & $\log (\mathrm{N})$ \\
\hline 3.0 & 114 & 0.786207 & 0.240535 & -0.61882 \\
3.6 & 2 & 0.8 & 0.223144 & -0.65142 \\
3.7 & 1 & 0.806897 & 0.21456 & -0.66845 \\
3.8 & 4 & 0.834483 & 0.180943 & -0.74246 \\
3.9 & 1 & 0.841379 & 0.172713 & -0.76268 \\
4.0 & 4 & 0.868966 & 0.140452 & -0.85247 \\
4.1 & 1 & 0.875862 & 0.132547 & -0.87763 \\
4.2 & 1 & 0.882759 & 0.124703 & -0.90412 \\
4.3 & 2 & 0.896552 & 0.109199 & -0.96178 \\
4.5 & 2 & 0.910345 & 0.093932 & -1.02719 \\
4.6 & 1 & 0.917241 & 0.086385 & -1.06356 \\
4.7 & 2 & 0.931034 & 0.071459 & -1.14594 \\
4.8 & 1 & 0.937931 & 0.064079 & -1.19329 \\
4.9 & 1 & 0.944828 & 0.056753 & -1.24601 \\
5.0 & 1 & 0.951724 & 0.04226 & -1.30557 \\
5.4 & 1 & 0.958621 & 0.027974 & -1.37407 \\
5.5 & 1 & 0.972414 & 0.027974 & -1.55325 \\
5.6 & 2 & 0.97931 & 0.020907 & -1.67971 \\
5.7 & 1 & 0.986207 & 0.013889 & -1.85733 \\
6.0 & 0.993103 & 0.00692 & -2.15987 \\
\hline
\end{tabular}

\subsection{Recurrence Relation Analysis}

Using the least squares method the regression coefficients, "a" and "b" of Gutenberg- Richter relation, (Eq. 2) have been calculated and is shown here in Fig.4. 


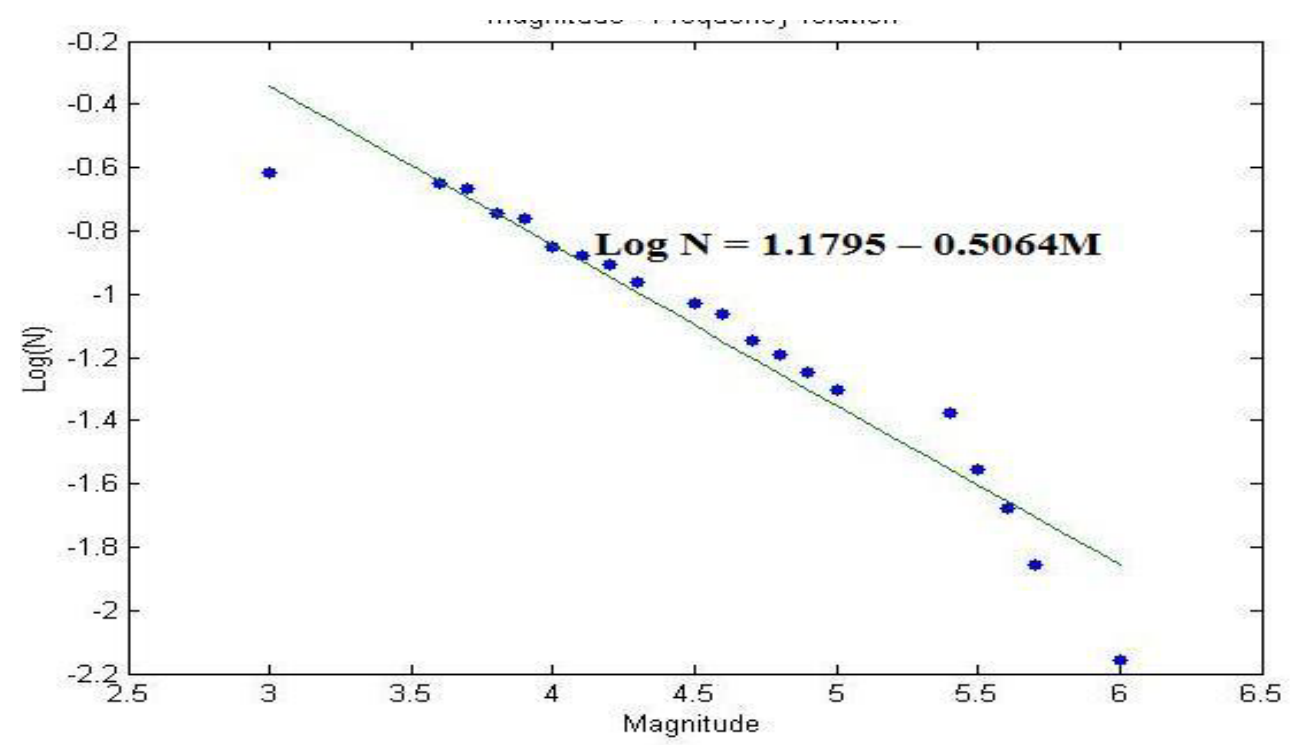

Figure 4. Earthquake Frequency Magnitude plot

Table 3. The probabilities of earthquake occurrence for this seismic source

\begin{tabular}{|c|c|c|c|c|c|c|c|}
\hline $\mathrm{M}$ & $\mathrm{N}(\mathrm{M})$ & $\mathrm{R} 1$ & $50 \mathrm{~N}$ & $\mathrm{R} 50$ & $100 \mathrm{~N}$ & $\mathrm{R} 100$ & $\mathrm{Tr}$ \\
\hline 4.0 & 0.14251 & 0.13821 & 7.125501 & 0.999196 & 14.251 & 0.999999 & 7.017051 \\
\hline 4.5 & 0.079549 & 0.076468 & 3.977465 & 0.981267 & 7.95493 & 0.999649 & 12.57082 \\
\hline 5.0 & 0.044405 & 0.043433 & 2.220227 & 0.891416 & 4.440454 & 0.988209 & 22.52022 \\
\hline 5.5 & 0.024787 & 0.024482 & 1.239334 & 0.710423 & 2.478668 & 0.916145 & 40.34425 \\
\hline 6.0 & 0.013836 & 0.013741 & 0.691798 & 0.499325 & 1.383596 & 0.749325 & 72.27542 \\
\hline 6.5 & 0.007723 & 0.007694 & 0.386163 & 0.32034 & 0.772325 & 0.538062 & 129.4791 \\
\hline 7.0 & 0.004311 & 0.004302 & 0.215557 & 0.193907 & 0.431113 & 0.350215 & 231.9576 \\
\hline
\end{tabular}

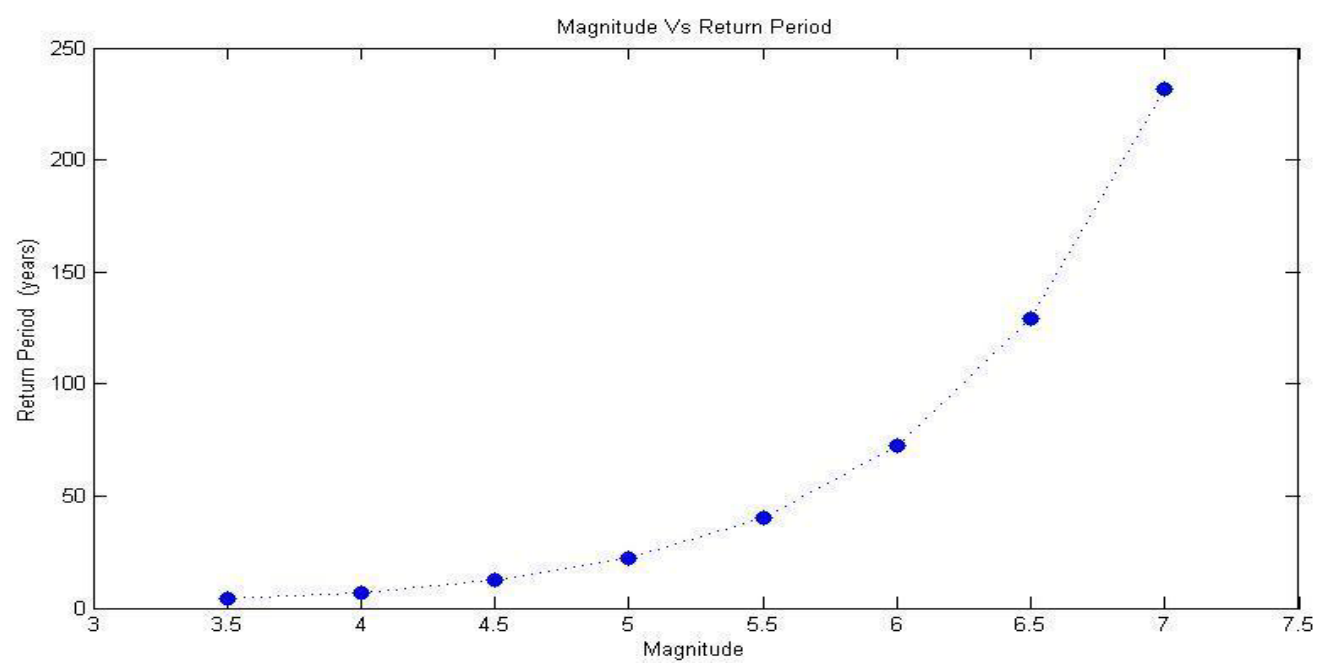

Figure 5. Trend curve of magnitude vs. return period of earthquakes.

The earthquake frequency- magnitude relation is shown below :

$$
\log \mathrm{N}=1.1795-0 .
$$

Using the above frequency- magnitude relation, Gumbel's regressions coefficients $(\alpha, \beta)$ have been calculated as:

$$
\begin{gathered}
\alpha=10^{\mathrm{a}}=10^{1.1795}=15.1188 \\
\beta=\mathrm{b} / \text { loge }=1.1661
\end{gathered}
$$

Further the earthquake number greater than a certain 
magnitude $\mathrm{M}$ for one year $(\mathrm{N}(\mathrm{M}))$, risk for one year (R1) and for (RD) year have been calculated using the following formulas:

$$
\begin{gathered}
\mathrm{N}(\mathrm{M})=\alpha(\exp -\beta \mathrm{M}) \\
\mathrm{R} 1(\mathrm{M})=1-\mathrm{e}^{-\mathrm{N}(\mathrm{M})} \\
\mathrm{RD}(\mathrm{M})=1-\mathrm{e}^{-\mathrm{DN}(\mathrm{M})}
\end{gathered}
$$

Finally the probabilities of earthquake occurrence for this seismic zone have been calculated for magnitudes $\mathrm{M}=5.0$, $5.5,6.0,6.5,7.0$ for periods $(\mathrm{T})=1,50,100$ years and are presented in table 3 .

The results in the above table show that there is 35 percent probability that an earthquake of magnitude greater than (M) $=6$ and above will occur in next $100-120$ years. However the return period for the earthquake is 231.95 years which is far greater than the seismic history considered. Fig.5 shows the trend of return period of various earthquake magnitude.

\section{Conclusions}

The seismic events in the region are highly scattered and are not associated with tectonic features or faults in the region. This shows the typical seismicity characteristics of Stable Continental Region (SCR). Annual earthquake energy release pattern indicates that earthquake of magnitude 6 may occur around 2060.The analysis and application of extreme value theory to earthquake data has shown that there is very high probability of occurrence of seismic events of magnitude in the range 4 to 4.5 in a time interval of 50 years and this probability decreases for the higher magnitudes. Where as the return period for magnitudes 6 and above is quite high which is about 100 years. But for the lower magnitudes it is 7 to 22 years which should be a matter of concern to builders and engineers. However it is desirable to go for the macro seismic field data collection and analyze them in the light of the present findings for further confirmation and seismic risk assessment.

\section{Acknowledgements}

Authors express their thanks to Director, Indian School of Mines (ISM), Dhanbad for extending all the facilities and encouragement to carry out the present work.

\section{REFERENCES}

[1] Gumbel, E.J., 1956, Statistical Theory of Extreme Value and Some Practical Applications ,National Bureau of Standards, Appl. Math, Ser 32 Washington.

[2] Gutenberg, B., Richter, C.F., 1956, Earthquake Magnitude, Intensity, Energy and Acceleration,Bull. Seism. Soc. of America, Vol. 32, No.3 pp 105-145.

[3] http://www.usgs.gov/

[4] Mahadevan T M (ed), 2002, Geology of Bihar \& Jharkhand, Geological Society of India pp1-559.

[5] Narula P.L., Acharyya S. K. and Banerjee J. (Ed.), 2000, Seismotectonic Atlas of India and Its Environs, (Ed.), Geological Survey of India.

[6] Karnik V and Schenkova Z, 1974 ,Application of Theory of Largest Values to Earthquake Occurrence in the Balkan Region, Studia Geoph.et geology ,18. Rao

[7] Schenkova Z. and Karnik V.,1970 , The Probability of occurrence of Largest Earthquake in European Area -Part II, Pure and Applied Geophysics, Vol 80 pp 152-161.

[8] Srivastava V. K. , Chouhan R. K. S. and Nigam Rajiv,1976, Largest Value Theory Applied to Probability of Earthquake Occurrence, Bulletin of Indian Society of Earthquake Technology (ISET), Vol 13, No ,pp 19-23.

[9] Tezcan, S.S., 1996, Probability Analysis of Earthquake Magnitudes, Turkish Earthquake Foundation, 26p 